\title{
LACTIC ACID BACTERIA ISOLATED FROM LOCALLY PRODUCED VINEGARS AND THEIR ANTIBACTERIAL ACTIVITY AGAINST FOODBORNE BACTERIA
}

\author{
AGNES LEE CHIU NEE ${ }^{1}$, MOHD NIZAM LANI ${ }^{1 *}$, ROZILA ALIAS² ${ }^{2}$ NDD ZAITON HASSAN ${ }^{\text {C3 }}$ \\ ${ }^{I}$ School of Food Science and Technology, Universiti Malaysia Terengganu, \\ 21030 Kuala Nerus, Terengganu, Malaysia. \\ ${ }^{2}$ International Halal Institute Universiti Selangor, Universiti Selangor, Seksyen 7, \\ 40000 Shah Alam, Selangor, Malaysia. \\ ${ }^{3}$ Faculty of Science and Technology, Universiti Sains Islam Malaysia (USIM), 71800 Bandar Baru Nilai, Nilai, \\ Negeri Sembilan, Malaysia.
}

*Corresponding author: nizamlani@umt.edu.my

\begin{abstract}
Vinegars are most widely used as preservatives in food industry. Vinegars are known for their health benefits; however, the roles of vinegar-associated microflora in locally produced vinegars are not well established. The objectives of this study are to isolate and identify the lactic acid bacteria (LAB) from black rice vinegar and coconut vinegar, measure their $\mathrm{pH}$ and titratable acidity, and determine their antibacterial activity. LAB was isolated using cultural method. Phenotypic characterization of LAB was carried out using Gram-staining, oxidase test, catalase test and API 50 CHL Kit. Results from API 50 CHL Kit confirmed that BRV03M strain from black rice vinegar and CV03M strain from coconut vinegar were Lactobacillus paracasei ssp. paracasei. The identified bacteria in both samples were consistent as L. paracasei using 16S rDNA gene sequences with $93 \%$ and $99 \%$ similarity, respectively. The $\mathrm{pH}$ and titratable acidity percentage of both vinegars were also determined. The stability of Cell Free Supernatant-Lactic Acid Bacteria (CFS-LAB) strains within 14 days on their inhibition against selected pathogenic bacteria was determined using agar well diffusion method. The CFS-LAB strain isolated from black rice vinegar (BRV03M) was more stable within 14 days than coconut vinegar in inhibiting tested bacteria, suggesting this strain has great potential as natural antibacterial agents.
\end{abstract}

Keywords: antibacterial activity, black rice vinegar, coconut vinegar, $\mathrm{pH}$, titratable acidity

\section{Introduction}

Vinegar is a product of two-stage successive microbial fermentation involving carbohydrate fermentation by yeasts to produce ethanol, followed by oxidative fermentation of ethanol by lactic acid bacteria (LAB) and acetic acid bacteria (AAB) to produce acetic acid (Yetiman \& Kesmen, 2015). The varieties of vinegars can be defined based on the different types of raw materials used in their production. Black rice vinegar (kurosu) is produced by rice saccharification, alcohol fermentation, and oxidative fermentation of ethanol to acetic acid. Kurosu is produced using either submerged fermentation process or traditional static fermentation (Murooka et al., 2009).

Coconut vinegar is usually low in acidity compared to other vinegars and used widely in the cooking of Thai dishes. It has a musty flavour with a very unique aftertaste. The production of coconut vinegar involves sugar of the coconut sap or the mature coconut water fermented to ethanol within 8-12 hours by yeasts and lactic acid bacteria. Formation of ethanol creates a highly suitable medium for the growth of acetic acid bacteria (AAB). During fermentation, the acetic acid bacteria appear after 2-3 days. The microbial diversity in this vinegar reflects the variety of raw materials, sugar sources and processes, as well as the diversity of the physicochemical characteristics such as temperature, $\mathrm{pH}$, and water activity. Nanda et al (2001) has reported detailed analysis of microorganisms during kurosu fermentation which belongs to Acetobacter pasteurianus.

Previous study has highlighted the roles of acetic acid bacteria $(\mathrm{AAB})$ in vinegars (Murooka \& Yamshita, 2008). AAB are usually the only bacteria that can grow and survive in fermenting vinegar broth that contains more than 2 to $3 \%$ acetic acid. Based on a report by Murooka \& Yamshita (2008), Acetobacter pasteurianus are the dominant bacteria in black rice vinegar. Perumpuli et al. (2014) have isolated Acetobacter pasteurianus and Gluconobacter frateurii from coconut vinegar.

$\mathrm{LAB}$ are the brewery bacteria that are normally found in vinegars and fermented products (Liu \& Han, 2014). LAB comprise of an ecologically diverse group of non-sporing Gram positive bacteria and produce lactic acid as primary metabolites of growth of either homofermentative or heterofermentative pathways (Fugelsang \& Edwards, 2007). LAB are rod-shaped or cocci-shaped Gram-positive, acid-tolerant, non-spore forming, anaerobic bacteria that share common metabolic and physiological characteristics (Aween et al., 2012). LAB can produce bioactive components such 
as organic acid, free fatty acids, ethanol, benzoate, enzymes, hydrogen peroxide, antimicrobial peptides and antibiotics that have inhibitory spectrum against pathogenic bacteria (Olofssonet al., 2016; Lani et al., 2015). These bacteria have strong antagonistic activity against bacteria and fungi (Aween et al., 2012, Bulgasem et al., 2016, Bulgasem et al., 2017). As there are limited studies on LAB isolated from locally produced vinegars, this study was carried out to isolate, identify and characterise the microbiological and chemical properties and their antibacterial activity against foodborne bacteria.

\section{Materials and Methods Vinegar Samples}

The samples used in this study were obtained from traditional homemade vinegars. In Northeast region of Malaysia, coconut vinegar is widely found and produced manually in villages in Penang, whereas the black rice vinegar is locally produced by a factory in Perak, Malaysia.

\section{Isolation of LAB from Vinegar Samples}

Firstly, $10 \mathrm{ml}$ of vinegar samples with $90 \mathrm{ml}$ of the de Man Rogosa Sharpe (MRS) broth were incubated anaerobically at $30^{\circ} \mathrm{C}$ for $24-48 \mathrm{~h}$ (Aween et al., 2012). Serial dilution was carried out by adding $1 \mathrm{ml}$ of samplebroth solution into $9 \mathrm{ml}$ of $0.1 \%$ buffered peptone water (BPW). Then, $0.1 \mathrm{ml}$ of diluent was spread on MRS agar plates and incubated anaerobically at $30^{\circ} \mathrm{C}$ for $24-48 \mathrm{~h}$. All isolates were checked for catalase negative and Gram-positive bacteria. Catalase test and oxidase test are orientation tests prior to the selection of API kit.

\section{Identification of LAB using API 50 CHL}

All presumptive LAB isolates were identified phenotypically by using API CHL 50 kit (API system, BioMerieux, France) following the methods described by the manufacturer. Strips were incubated at $37^{\circ} \mathrm{C}$ as recommended by the manufacturer. Changes in colors either to yellow or blue were recorded after 24 and $48 \mathrm{~h}$ and the results were analyzed based on numerical profiles and the these profiles were interpreted using API Web ${ }^{\mathrm{TM}}$ (BioMerieux, France).

\section{Polymerase Chain Reaction of $L A B$}

An overnight culture cells grown in $20 \mathrm{~mL}$ MRS broth incubated at $30^{\circ} \mathrm{C}$ were used for total genomic DNA extraction using Qiagen Mini DNA Extraction Kit (Germany) following the methods described by the manufacturer. The preparation of PCR of samples was according to the method described by Yetiman \& Kesmen, 2015. Each sample of purified DNA of LAB isolates was processed to the PCR using BiotekePowerTaq 2X MasterMix (Biolution ${ }^{\circledR}$ company). The primers used were WBAC1 (5'- GTC
GTC AGC TCG TGT CGT GAG A - 3') and WBAC2 (5'- CCC GGG AAC GTA TTC ACC GCG - 3'). The setting of PCR was carried out as follows: initial at $95^{\circ} \mathrm{C}$ for $5 \mathrm{~min}$, denaturation at $92^{\circ} \mathrm{C}$ for $30 \mathrm{~s}$, annealing at $67^{\circ} \mathrm{C}$ for $1 \mathrm{~min}$ and extension at $72^{\circ} \mathrm{C}$ for $30 \mathrm{~s}$, with 30 cycles for each step and a final extension at $72^{\circ} \mathrm{C}$ for 5 min. A $2 \mu \mathrm{L}$ of each amplification mixture was subjected to electrophoresis in $0.8 \%(\mathrm{w} / \mathrm{v})$ agarose gels in $1.0 \times$ TBE buffer for $45 \mathrm{~min}$ and $75 \mathrm{~V}$. Then, the gel was stained using Sybr safe DNA stain (Invitrogen, Germany) and was visualized to clear band and photographed with e-gel imager with blue light based (BioRAD, USA). The partial 16S rDNA sequences were determined by Apical Scientific Sdn. Bhd. Malaysia and sequences were compared with databases (Gen-Bank).

\section{pH and Titratable Acidity}

The $\mathrm{pH}$ values of the vinegars were measured using digital $\mathrm{pH}$ meter and the titratable acidity (TA) of both vinegars were determined as $\mathrm{ml}$ of $1 \mathrm{~N} \mathrm{NaOH}$ used to obtain a pink colour endpoint with phenolphthalein (AOAC, 2000). The black rice vinegar was prepared by diluting with distilled water at 1:29 ratio. The equation to calculate $\mathrm{TA} \%$ as acetic acid is as follows:

$$
\% \mathrm{TA}=\frac{(\mathrm{ml} \text { of } \mathrm{NaOH}) \times(\mathrm{N} \text { of } \mathrm{NaOH}) \times(60.05)}{10 \times \text { Sample Weight }}
$$

\section{Antibacterial activity of LAB}

\section{Preparation of Cells Free Supernatant from $L A B$}

LAB isolates were inoculated into de Man Rogosa and Sharpe (MRS) broth (Oxoid, CM0359, United Kingdom) and incubated for $24-48$ hours at $30^{\circ} \mathrm{C}$ in anaerobic incubator. The LAB-CFS was prepared by centrifuging the broth at $10000 \mathrm{rpm}$ for 1 minute at $27^{\circ} \mathrm{C}$. The supernatant of CFS-LAB was kept at $4^{\circ} \mathrm{C}$ until further used.

\section{Quantitative Evaluation for Antibacterial Activity by Agar Well Diffusion Method}

Antibacterial activity of the LAB isolates against foodborne bacteria was determined using the agar well diffusion method as described by Balouiri et al.,(2015). Initially, LAB strains were cultured in de Man Rogosa and Sharpe (MRS) broth and incubated anaerobically at $30^{\circ} \mathrm{C}$ for $24-48 \mathrm{~h}$ to obtain the supernatant. The foodborne bacteria were swabbed onto the Mueller Hilton Agar (MHA) plates and several wells with a diameter of 6 to 8 were punched using a sterile cork's borer. Then, $50 \mu \mathrm{L}$ of CFS-LAB and streptomycin were inserted into the wells as tested samples and positive control respectively and incubated aerobically at $30^{\circ} \mathrm{C}$ for $24 \mathrm{~h}$. Clear zone indicative of bacteria inhibition was measured ( $\mathrm{mm})$. The experiment was done in duplicate. The antibacterial activity was monitored for a period of 14 days to observe the stability of CFS-LAB against foodborne bacteria. 


\section{Statistical Analysis}

Minitab 17 was used to analyze raw data of growth inhibition against foodborne bacteria by CFS-LAB isolated from vinegars. One-way ANOVA was chosen in order to determine the significant effect of a factor (types of sample). Then, the means were further analysed using Fisher's test to identify the significant difference between means at $\mathrm{p} \leq 0.05$ for different samples. The statistical analyses were performed using Minitab 17 software.

\section{Results and Discussion Isolation and Identification of $L A B$}

Two LAB isolates from coconut vinegar and black rice vinegar samples were further identified. These isolates showed colonies creamy white in colore elevated, entire and circular shaped on the MRS agar, catalase negative and oxidase negative. All organisms were observed under a light microscope using 1000x magnification and confirmed as Gram positive rod.

\section{Phenotypic and Genotypic Identification LAB Isolates}

Phenotypic identification of the LAB isolates using API 50 CHL kit showed that the isolates of Black Rice Vinegar (BRV03M) and Coconut Vinegar (CV03M) had $92.3 \%$ to $99.5 \%$ similarity to $L$. paracasei $\mathrm{ssp}$. paracasei 2 as shown in Table 1.

Table 1: Identification of LAB isolates using API 50 CHL kit

\begin{tabular}{l|l|l|l}
\hline Sample & Similarity & Identification using API 50 CHL & Level of identification \\
\hline BRV03M & $92.3 \%$ & L. paracasei ssp. paracasei 2 & Very Good Identification \\
\hline CV03M & $99.5 \%$ & L. paracasei ssp. paracasei 2 & Very Good Identification \\
\hline
\end{tabular}

For genotypic identification using 16S rDNA, it was found that $L$. paracasei had the highest percentage of similarity, which was similar to API 50 CHL results (Table 2). For example, the isolates BRV03M had 93\% similarity to $L$. paracasei compared to L. rhamnosus and
L. casei (both had $92 \%$ similarity). For strains of coconut vinegar (CV03M), L. paracasei also showed the highest similarity. Therefore, both strains were confirmed as $L$. paracasei.

Table 2: Identification of LAB isolates using 16S rDNA

\begin{tabular}{cccc}
\hline \multirow{2}{*}{ LAB isolates } & \multicolumn{3}{c}{ 16S rDNA } \\
\cline { 2 - 4 } & Similarity & Identification & Accession \\
\hline \multirow{3}{*}{ Black rice vinegar } & $\mathbf{9 3 \%}$ & L.paracasei & MF611813.1 \\
& $92 \%$ & L.rhamnosus & KP942850.1 \\
& $92 \%$ & L.casei & MF108773.1 \\
\hline \multirow{3}{*}{ Coconut vinegar } & $\mathbf{9 9 \%}$ & Lactobacillus paracasei & KX388386.1 \\
& $99 \%$ & L.rhamnosus & MG685875.1 \\
& $99 \%$ & L.casei & MF108773.1 \\
\hline
\end{tabular}




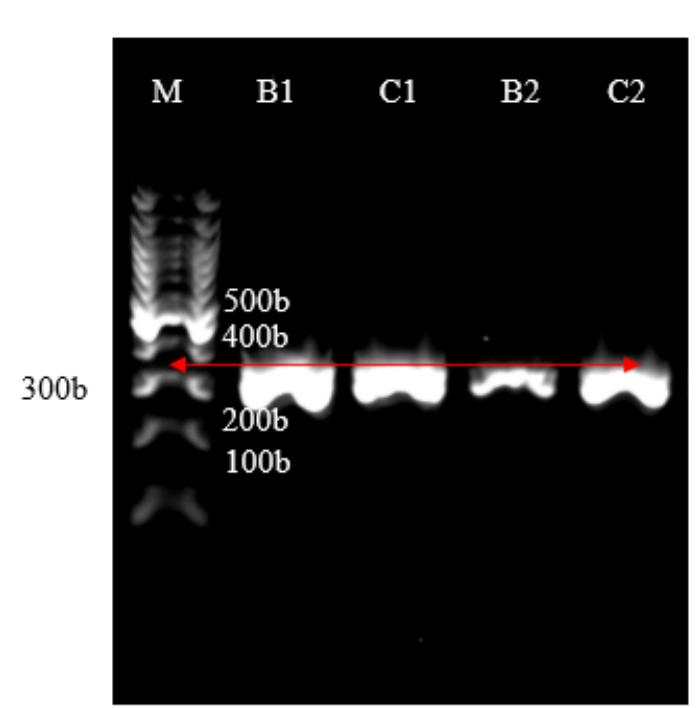

*Note:

Primers: WBAC1 and WBAC2

M: Marker Ladder

Sample B1 and B2 (Black Rice Vinegar, BR03M in

duplicate)

Sample C1 and C2 (Coconut Vinegar, CV03M in duplicate)

Figure 1: Visual of LAB gel by e-gel image (blue-light based)

\section{pH and Titratable Acidity}

The $\mathrm{pH}$ values of all three locally produced vinegar were obtained by using digital $\mathrm{pH}$ meter. As shown in Table 3 , black rice vinegar had lower $\mathrm{pH}$ than coconut vinegar. The higher the $\mathrm{pH}$ value, the lower the acidity of the vinegar. The titratable acidity (TA) percentages of the three locally produced vinegar were obtained, and black rice vinegar had the highest acidity. Black rice vinegar had higher percentage of TA $(5.46 \%)$ than coconut vinegar $(1.54 \%)$. The $\mathrm{pH}$ value and titratable acidity of both vinegars showed positive relationship with their antibacterial properties. This finding was in agreement with the research conducted by Ewadh, et al. (2013) who reported that antibacterial activity of vinegar was attributed to direct $\mathrm{pH}$ reduction of the substrate.

Table 3: $\mathrm{pH}$ value and titratable acidity (\%) of locally produced vinegar sample.

\begin{tabular}{c|c|c}
\hline Sample & pH value & Titratable acidity (\%) \\
\hline Coconut vinegar & $3.56 \pm 0.02$ & 1.54 \\
\hline Black Rice vinegar & $2.64 \pm 0.01$ & 5.46 \\
\hline
\end{tabular}

\section{Quantitative Evaluation for Antibacterial Activity by Agar Well Diffusion Method}

Agar well diffusion method is one the promising methods to determine the antibacterial activity. In this study, Streptomycin with concentration of $0.01 \mathrm{~g} / \mathrm{ml}$ was used as the control. The inhibitory effect shown by Streptomycin is due to its effects on ribosomes through inhibition or faulty synthesis to cellular proteins of the pathogenic bacteria (Kogut \& Harris, 1969). Streptomycin also has high degree of toxicity and exhibits strong action against certain Gram-negative and Gram-positive bacteria in vivo (Robinson, 2014). The stability of CFS-LAB in inhibiting foodborne pathogenic bacteria was monitored for 14 days.
Table 4 shows the inhibition activity of CFS-LAB of $L$. paracasei against $E$. coli ATCC 11775 . The CFS of $L$. paracasei isolated from black rice vinegar showed inhibition activity that ranged from $10 \pm 0.0 \mathrm{~mm}$ to $15 \pm$ $1.0 \mathrm{~mm}$ where no inhibition activity against $E$. coli was observed at day-3 and day-5. The CFS-LAB isolated from coconut vinegar exhibited inhibition activity that ranged from $12.0 \pm 1.0 \mathrm{~mm}$ to $14.7 \pm 0.6 \mathrm{~mm}$ against the growth of $E$. coli, but no inhibition was observed at day1, day-3 and day-11. The range of inhibition against $E$. coli was in agreement with study by Rahman et al., (2017) who reported inhibitory effect against the growth $E$. coli with inhibition zone that ranged from 5-17 mm. 
LACTIC ACID BACTERIA ISOLATED FROM LOCALLY PRODUCED VINEGARS AND THEIR ANTIBACTERIAL ACTIVITY AGAINST FOODBORNE BACTERIA

Table 4: Antibacterial activity of LAB against E. coli (ATCC 11775)

\begin{tabular}{lccccccc}
\hline Pathogens & \multicolumn{7}{c}{ E. coli (ATCC 11775) } \\
\hline $\begin{array}{l}\text { Inhibition Zone } \\
(\mathrm{mm})\end{array}$ & Day 1 & Day 3 & Day 5 & Day 7 & Day 9 & Day 11 & Day 14 \\
Positive control & $31.7 \pm 1.2$ & $45 \pm 1.0$ & $34.7 \pm 1.5$ & $26.7 \pm 1.2$ & $36.3 \pm 2.1$ & $35.7 \pm 2.1$ & $35.3 \pm 2.5$ \\
Sample BRV03M & 10 & - & - & $15 \pm 1.0$ & $13 \pm 1.0$ & $13 \pm 0.0$ & $12.7 \pm 0.6$ \\
Sample CV03M & - & - & $13.7 \pm 0.6$ & $14.7 \pm 0.6$ & $12.7 \pm 0.6$ & - & $12.0 \pm 1.0$ \\
\hline Positive control = Streptomycin $(0.1 \mathrm{mg} / \mathrm{ml})$ & & & & & \\
Control of each plate= 0mm & & & & & \\
Mean diameter of inhibition zone $(\mathrm{mm})$ after 24hour incubation at 30 $0^{\circ} \mathrm{C}$ \\
* (-) indicates no inhibition zones; $\leq 15 \mathrm{~mm}$ (low effect); $16-20 \mathrm{~mm}$ (moderate effect); \\
$\geq 21 \mathrm{~mm}$ (strong effect)
\end{tabular}

Isolates of $\mathrm{LAB}$ from both coconut vinegar and black rice vinegar possessed weak inhibitory effect against $B$. cereus ATCC 11778 compared to the positive control, streptomycin (Table 5). The CFS of L. paracasei isolated from black rice vinegar exhibited inhibition diameter that ranged from $9.0 \pm 1.0 \mathrm{~mm}$ to $15.0 \pm 1.0$ $\mathrm{mm}$ with no inhibition activity at day-3. The CFS-LAB of L. paracasei isolated from coconut vinegar showed inhibition activity that ranged from $13.7 \pm 0.6 \mathrm{~mm}$ to $16.0 \pm 1.0 \mathrm{~mm}$ with no inhibition activity at day- 1 , day3 , day-5, and day-11. The range of inhibition activity was similar to a report by Rahman et al. (2017) who found inhibitory effect against $B$. cereus with $8-18 \mathrm{~mm}$.

Table 5: Antibacterial activity of LAB against B. cereus (ATCC 11778)

\begin{tabular}{lccccccc}
\hline Pathogens & \multicolumn{7}{c}{ B. cereus (ATCC 11778) } \\
\hline Inhibition Zone & Day 1 & Day 3 & Day 5 & Day 7 & Day 9 & Day 11 & Day 14 \\
(mm) & & & & & & & \\
Positive control & $36.7 \pm 1.2$ & $45.3 \pm 2.1$ & $34.7 \pm 1.2$ & $33.7 \pm 0.6$ & $42.0 \pm 1.0$ & $35.7 \pm 2.1$ & $30.0 \pm 2.0$ \\
Sample BRV03M & $9.0 \pm 1.0$ & - & $13.0 \pm 0$ & $14.7 \pm 1.2$ & $10.3 \pm 0.6$ & $15.0 \pm 1.0$ & $13.0 \pm 1.0$ \\
Sample CV03M & - & - & - & $14.7 \pm 1.2$ & $13.7 \pm 0.6$ & - & $16.0 \pm 1.0$ \\
\hline Positive control = Streptomycin $(0.1 \mathrm{mg} / \mathrm{ml})$ & & & & & \\
Control of each plate= 0mm & & & & & \\
Mean diameter of inhibition zone $(\mathrm{mm})$ after 24hour incubation at 30 & ${ }^{\circ} \mathrm{C}$ \\
* (-) indicates no inhibition zones; $\leq 15 \mathrm{~mm}$ (low effect); $16-20 \mathrm{~mm}$ (moderate effect); \\
$\geq 21 \mathrm{~mm}$ (strong effect)
\end{tabular}

(Vlková et al., 2006)

Table 6 exhibits the antibacterial activity of CFSLAB in black rice vinegar and coconut vinegar against S. aureus ATCC 33862. The inhibition activity of CFSLAB from black rice vinegar against $S$. aureus ranged from $10.3 \pm 0.6 \mathrm{~mm}$ to $14.3 \pm 1.5 \mathrm{~mm}$, with no inhibition activity at day-5. The inhibition activity of CFS-LAB isolated from coconut vinegar ranged from $9.0 \pm 0.0 \mathrm{~mm}$ to $15.0 \pm 1.0 \mathrm{~mm}$ with no inhibition activity at day-1, day-5 and day-11. The result of this research was in agreement with previous study which stated that isolates of LAB exhibited antibacterial effect against the growth of $S$. aureus with 6-14 $\mathrm{mm}$ inhibition zone. 
LACTIC ACID BACTERIA ISOLATED FROM LOCALLY PRODUCED VINEGARS AND THEIR ANTIBACTERIAL ACTIVITY AGAINST FOODBORNE BACTERIA

Table 6: Antibacterial activity of LAB against $S$. aureus (ATCC 33862)

\begin{tabular}{lccccccc}
\hline Pathogens & \multicolumn{7}{c}{ S. aureus (ATCC 33862) } \\
\hline Inhibition Zone & Day 1 & Day 3 & Day 5 & Day 7 & Day 9 & Day 11 & Day 14 \\
(mm) & & & & & & & \\
Positive control & $34.3 \pm 1.5$ & $48.3 \pm 1.5$ & $37.7 \pm 1.5$ & $34.7 \pm 0.6$ & $36.7 \pm 1.5$ & $37.7 \pm 1.2$ & $38.3 \pm 2.1$ \\
Sample BRV03M & $13.7 \pm 0.6$ & $10.3 \pm 0.6$ & - & $11.3 \pm 1.2$ & $13.3 \pm 0.6$ & $14.3 \pm 1.5$ & $12.3 \pm 0.6$ \\
Sample CV03M & - & $9.0 \pm 0$ & - & $13.0 \pm 0.6$ & $12.0 \pm 0$ & - & $15.0 \pm 1.0$ \\
\hline Positive control = Streptomycin $(0.1 \mathrm{mg} / \mathrm{ml})$ & & & & & \\
Control of each plate= 0mm & & & & & \\
Mean diameter of inhibition zone $(\mathrm{mm})$ after 24hour incubation at 30 ${ }^{\circ} \mathrm{C}$ & \\
* (-) indicates no inhibition zones; $\leq 15 \mathrm{~mm}$ (low effect); 16-20mm (moderate effect); \\
$\geq 21 \mathrm{~mm}$ (strong effect)
\end{tabular}

(VIkovó et al., 2006)

Antibacterial activity of LAB strains against $P$. aeruginosa ATCC 10145 is shown in Table 7. The inhibition of CFS-LAB from black rice vinegar against $P$. aeruginosa ranged from $9.0 \pm 1.0$ to $16.3 \pm 0.6 \mathrm{~mm}$, whereas the inhibition of CFS-LAB from coconut vinegar against $P$. aeruginosa ranged from $10.0 \pm 1.0$ to $15.3 \pm 0.6 \mathrm{~mm}$ with no inhibition activity at day- 1 . The results were supported by previous finding where the growth of $P$. aeruginosa, $B$. cereus, and $S$. aureus were inhibited by the CFS-LAB of $L$. paracasei. The inhibition against $P$. aeruginosa strain was attributed to the low $\mathrm{pH}$ by the undissociated lactic acid and production of other primary and secondary antimicrobial metabolites by LAB (Okorhi, 2014).

Table 7: Antibacterial activity of LAB against $P$. aeruginosa (ATCC 10145)

\begin{tabular}{lccccccc}
\hline Pathogens & \multicolumn{7}{c}{ P. aeruginosa (ATCC 10145) } \\
\hline $\begin{array}{l}\text { Inhibition Zone } \\
(\mathrm{mm})\end{array}$ & Day 1 & Day 3 & Day 5 & Day 7 & Day 9 & Day 11 & Day 14 \\
Positive control & $29.3 \pm 2.1$ & $32.3 \pm 0.6$ & $29.7 \pm 1.2$ & $23.0 \pm 1.0$ & $26.7 \pm 1.2$ & $30.0 \pm 1.7$ & $25.3 \pm 0.6$ \\
Sample BRV03M & $9.0 \pm 1.0$ & $11.3 \pm 0.6$ & $13.0 \pm 0$ & $15.3 \pm 1.2$ & $12.0 \pm 1.7$ & $16.3 \pm 0.6$ & $12.0 \pm 1.0$ \\
Sample CV03M & - & $10.0 \pm 1.0$ & $13.7 \pm 0.6$ & $15.3 \pm 0.6$ & $12.0 \pm 0$ & $13.0 \pm 1.0$ & $13.3 \pm 1.2$ \\
\hline Positive control = Streptomycin $(0.1 \mathrm{mg} / \mathrm{ml})$ & & & \\
Control of each plate= 0mm \\
Mean diameter of inhibition zone $(\mathrm{mm})$ after 24hour incubation at 30 ${ }^{\circ} \mathrm{C}$ \\
* (-) indicates no inhibition zones; $\leq 15 \mathrm{~mm}$ (low effect); 16-20mm (moderate effect); \\
$\geq 21 \mathrm{~mm}$ (strong effect)
\end{tabular}

(Vlková et al., 2006)

Overall, the CFS-LAB of L. paracasei of black rice vinegar sample (BRV03M) was more stable than coconut vinegar $(\mathrm{CV} 03 \mathrm{M})$. Both LAB strains showed low to moderate antibacterial effect by possessed inhibition zone ranging from 8-16 $\mathrm{mm}$. The greater antibacterial activity of $L$. paracasei by BRV03M corresponded to its lower $\mathrm{pH}$ (2.64) and greater percentage of lactic acid as measured by titratable acidity $(5.46 \%)$. Lactic acid, a major metabolite produced by $L$. paracasei, is the major compound responsible for inhibiting pathogenic bacteria (Lozo et al., 2004). Mechanism of action by lactic acid against bacteria is similar to acetic acid. It involves disruption of cytoplasmic membrane and increase permeability of outer membrane of Gram-negative bacteria (Okorhi, 2014).

\section{Conclusion}

In conclusion, the isolation and identification of LAB using API 50 CHL and 16S rDNA isolated from black rice vinegar (BRV03M) and coconut vinegar (CV03M) confirmed it as Lactobacillus paracasei. The antibacterial activity of CFS-LAB of $L$. paracasei by BRV03M and CV03M strains against E. coli, B. cereus, $S$. aureus and $P$. aeruginosa showed moderate inhibitory effect against all the tested pathogens. The stability of CFS-LAB strain isolated from black rice vinegar in inhibiting pathogenic bacteria was higher within 14 days than coconut vinegar, suggesting this strain has great potential as natural antibacterial agents.

\section{Acknowledgement}

The authors thank the School of Food Science and Technology, UMT for funding this project. 


\section{References}

AOAC (2000). Official method 942.15 Acidity (Titratable) of fruit products read with A.O.A.C official method 920.149 Preparation of test sample, $17^{\text {th }}$ ed.

Aween, M. M., Hassan, Z., Muhialdin, B. J., Noor, H. M., \& Eljamel, Y. A. (2012). Evaluation on antibacterial activity of Lactobacillus acidophilus strains isolated from honey. American Journal of Applied Sciences, 9(6), 807.

Balouiri, M., Sadiki, M., \& Ibnsouda, S. (2016). Methods for in vitro evaluation antimicrobial activity: A review. Journal of Pharmaceutical Analysis, 6, 71-79.

Bulgasem, B.Y, Hassan, Z., Huda-Faujan, N., Omar, R.H.A., Lani, M.N., \& Alshelmani, M.I. 2017. Effect of $\mathrm{pH}$, heat treatment and enzymes on the antifungal activity of lactic acid bacteria against Candida species. Malaysian Journal of Microbiology, 13(3), 195-202.

Bulgasem, B.Y., Lani, M.N., Hassan, Z., Wan Yusoff, W.M., \& Fnaish, S.G. 2016. Antifungal activity of lactic acid bacteria strains isolated from natural honey against pathogenic Candida species. Mycobiology, 44(4), 302-309.

Ewadh, M., Hasan, H., Bnyan, I., Mousa, F., Sultan, J., $\&$ Ewadh, M., 2013. Antibacterial activity of 2-(2Hydroxy phenylimino) acetic acid. Life Science Technology, 7, 15-20.

Fugelsang, K., \& Edwards, C. (2007). Chapter 2: Lactic Acid Bacteria. In Wine Microbiology. Practical Applications and Procedures. Springer. pp 29-44.

Kogut, M., \& Harris, M. (1969). Effects of streptomycin in bacterial cultures growing at different rates; interaction with bacterial ribosomes in vivo. The FEBS Journal, 9(1), 42-49.

Lani, M., Nor, N., Ramli, N., Radhuan, Z., Rizan, M., Lokman, N., \& Hassan, Z. (2015). Effects of Incorporation of Lactic Acid Bacteria on Microbiological Quality and Shelf Life of Raw 'Satar'. In Beneficial Microorganisms in Food and Nutraceuticals (pp. 81-109). Springer, Cham.

Liu, S., \& Han, Y. (2014). Microbial diversity in fermented foods with emphasis on bacterial fermentation and health benefits. Microorganisms and Fermentation of Traditional Foods, 37.
Lozo, J., Vukasinovic, M., Strahinic, I., \& Topisirovic, L. (2004). Characterization and antimicrobial activity of bacteriocin 217 produced by natural isolate Lactobacillus paracasei subsp. paracasei BGBUK2-16. Journal of Food Protection, 67(12), 2727-2734.

Murooka, Y. \& Yamshita, M. (2008). Traditional healthful fermented products of Japan. Journal of Industrial Microbiology and Biotechnology, 35, 791798.

Nanda, K., Taniguchi, M., Ujike, S., Ishihara, N., Mori, H., Ono, H. \& Murooka, Y., 2001. Characterization of acetic acid bacteria in traditional acetic acid fermentation of rice vinegar (komesu) and unpolished rice vinegar (kurosu) produced in Japan. Applied and Environmental Microbiology, 67(2), 986-990.

Okorhi, B. (2014). Anti-pseudomonas activity of organic acids produced by lactic acid bacteria. Biological Sciences and Pharmaceutical Research, 2(9), 106114.

Olofsson, T. C., Butler, È., Markowicz, P., Lindholm, C., Larsson, L., \& Vásquez, A. (2016). Lactic acid bacterial symbionts in honeybees-an unknown key to honey's antimicrobial and therapeutic activities. International Wound Journal, 13(5), 668-679.

Perumpuli, D.A., Watanabe, T. \& Toyama, H. (2014). Identification and characterization of thermotolerant acetic acid bacteria strains isolated from coconut water vinegar in Sri Lanka. Bioscience, Biotechnology and Biochemistry, 78(3), 533-541.

Rahman, S. A., Kahar, A. A., Mansor, A., Murni, D. L., Hussin, A., Sharifudin, S., . . \& \& Long, K. (2017). Identification of potential indigenous microbe from local fermented vegetables with antimicrobial activity. RAZI Publishing, 1(1), 1-3.

Robinson, R. (2014). Encyclopedia of Food Microbiology. Academic press.

Vlkova E, Rada V, Popelarova P, Trojanová I, \& Killer J (2006) Antimicrobial susceptibility of bifidobacteria isolated from gastrointestinal tract of calves. Livestock Science, 105: 253-259.

Yetiman, A., \& Kesmen, Z. (2015). Identification of acetic acid bacteria in traditionally produced vinegar and mother of vinegar by using different molecular techniques. International Journal of Food Microbiology, 204, 9-16. 